\title{
Pyrolysis kinetics of biomass wastes using isoconversional methods and the distributed activation energy model
}

\author{
Cindy Natalia Arenas a , María Victoria Navarro b, Juan Daniel Martínez ${ }^{\text {a,* }}$ \\ ${ }^{a}$ Grupo de Investigaciones Ambientales (GIA), Universidad Pontificia Bolivariana (UPB), \\ Circular 1ra $N^{\circ}$ 74-50, Medellín, Colombia \\ ${ }^{b}$ Instituto de Carboquímica (ICB-CSIC), Miguel Luesma Castán 4, 50018, Zaragoza, Spain \\ *Corresponding author: juand.martinez@upb.edu.co
}

\begin{abstract}
In this work, a thermogravimetric analyser was used to assess the pyrolysis kinetics of pineapple, orange and mango peel wastes and agro-industrial by-products, rice husk and pine wood. Five isoconversional methods (KAS, FWO, Starink, Vyazovkin and Friedman) and one model-fitting method (DAEM) accurately fitted the experimental data at three heating rates $\left(5,10\right.$ and $\left.20^{\circ} \mathrm{C} / \mathrm{min}\right)$ between $10 \%$ and $90 \%$ conversion. These methods agree with the trends shown by the activation energy $\left(E_{a}\right)$ distribution calculated, with fluctuations between 150 and $550 \mathrm{~kJ} / \mathrm{mol}$. The fluctuations of $E_{a}$ in the whole range of conversion, in addition to a higher number of relevant reactions obtained by DAEM for fruit peel samples compared to agro-industrial samples, are associated with a higher extractive content in the peels. Kinetic parameters fitted by DAEM were successfully verified at the highest heating rate studied.
\end{abstract}

Keywords: biomass, pyrolysis, thermogravimetric analysis, isoconversional methods, kinetic models. 


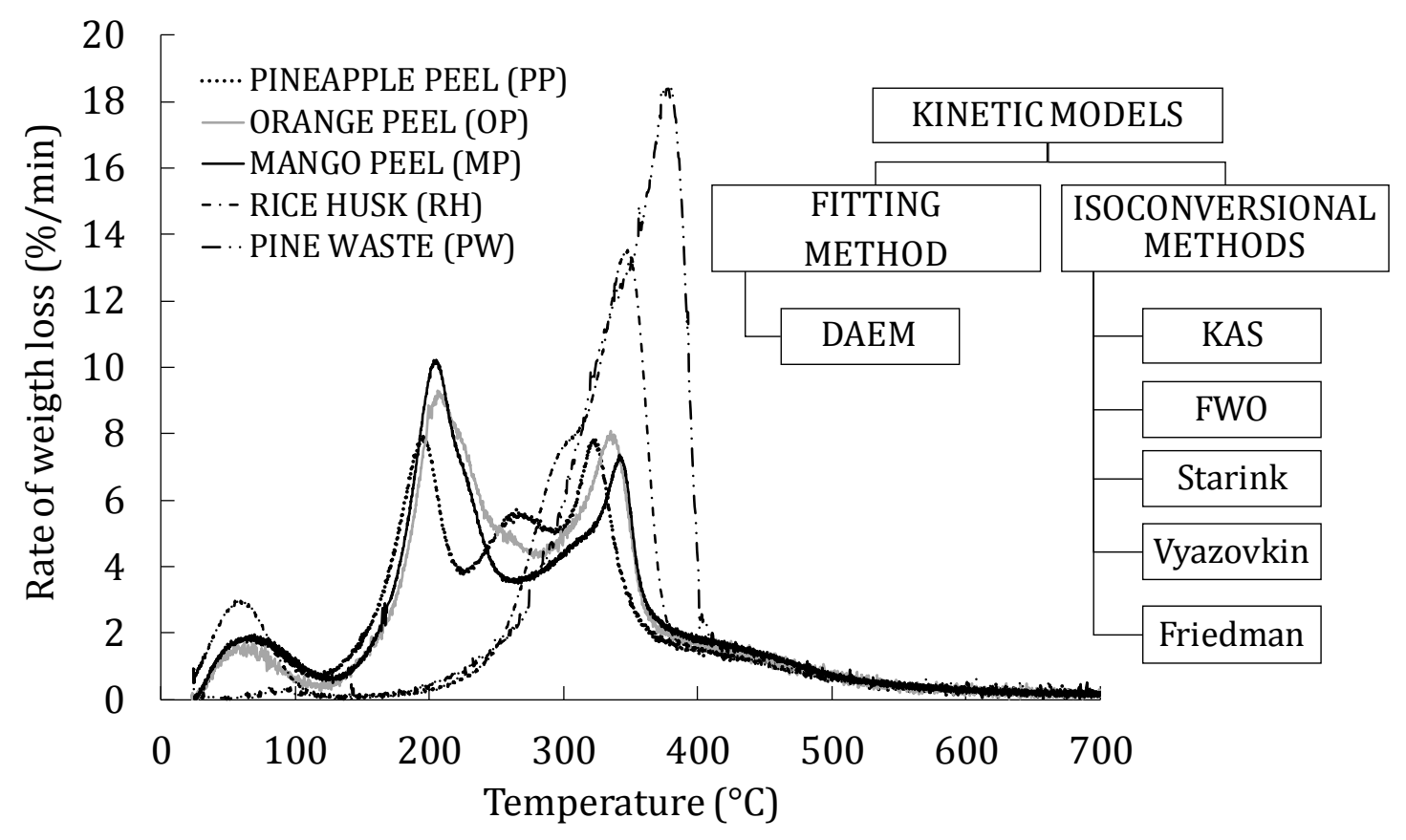




\section{Introduction}

Energy consumption is increasing worldwide every year, while the sources of fossil fuels are either dwindling or remaining constant. Moreover, the need to reduce the use of fossil fuels owing to increased $\mathrm{CO}_{2}$ emissions and to expand use of alternative fuels such those made from wastes (so-called second generation biofuels) has become common knowledge. Furthermore, biomass is the only renewable source able to produce electricity, heat, fuels and chemical products, making it a highly strategic resource with which to face the challenges of near future. Waste management systems in developing economies are still insufficient and in some cases cause environmental problems because waste tends to be unseparated and disposed of in open landfill sites. Biomass wastes, particularly those derived from food and agro-industry sector, are plentiful throughout the world, carbon-neutral, and can be regarded as a promising renewable energy resource.

In Colombia, approximately 741,300 tonnes of pineapple (Procolombia, 2017), 238,100 tonnes of oranges (FAO, 2017), 318,628 tonnes of mango (Procolombia, 2017), and 2.1 million tonnes of rough (paddy) rice were produced in 2015 (FAO, 2016). In addition, there are approximately 330,000 ha of land planted with pine species (Pérez et al., 2017). Pineapple, orange and mango peels represent 29-40\% (Ketnawa et al., 2012), 40-50\% (Oberoi et al., 2010) and 15-20\% (Ajilla et al., 2007) of the gross weight of the fruit, respectively, while rice husk represents $20-23 \%$ of the gross weight of the grain (Martinez et al., 2011). Currently, both fruit peel wastes and agro-industrial by-products are managed as wastes, squandering their potential for use as feedstocks in other industrial processes such as in biorefineries. 
Biomass and wastes can be transformed by thermochemical conversion processes such as pyrolysis, gasification and combustion. Besides being part of the first stages of the gasification and combustion processes, pyrolysis is gaining increasing attention given the possibility for producing a wide range of value-added products in the form of gases, liquids and solids, depending on the process conditions. Pyrolysis is generally an endothermic process performed in an oxygen-free atmosphere at temperatures of between $250^{\circ} \mathrm{C}$ and $600^{\circ} \mathrm{C}$. In particular, the pyrolysis of lignocellulosic biomass involves many chemical and physical phenomena, resulting in a large number of intermediate and final products. Roughly speaking, there are three distinct steps in the pyrolysis process: i) drying, ii) primary reactions where volatile products are released and iii) secondary reactions where the primary products are subject to other reactions (Neves et al., 2011).

The kinetic analysis of any feedstock under pyrolysis conditions provides essential information on how it decomposes, allowing the optimization of the process and providing valuable information for reactor design. Kinetic analysis also reveals important data on the mechanism of reaction and establishes mathematical models that can describe the process (Huang et al., 2017). Kinetic studies on biomass pyrolysis are very frequent in the literature and they are addressed by two approaches: i) model-free (isoconversional) methods and ii) model-fitting methods (Vyazovkin and Wight, 1999; Vyazovkin et al., 2011; Mishra and Mohanty, 2018; He at al., 2019).

Isoconversional methods have the potential to estimate the behaviour of complex reactions; they are simple in nature; and they minimize the risks of selecting an unsuitable kinetic model and of finding the wrong kinetic parameters. Isoconversional methods have been widely used to examine the non-isothermal kinetic parameters of 
solid feedstocks in the pyrolysis processes (Huang et al., 2017; He at al., 2019), and they represent the most effective way with which to process thermogravimetric analysis (TGA) data in order to calculate effective activation energies for biomass pyrolysis (Cai et al., 2018). In addition, isoconversional methods constitute an interesting and easy-touse solution for the estimation of kinetic parameters, providing rather accurate results in the case of a one-step reaction (Damartzis et al., 2011), with errors lower than $1 \%$ (Mishra and Mohanty, 2018). All isoconversional methods are based on the principle that the reaction rate at constant conversion degree is only a function of temperature (Vyazovkin et al., 2011). It is usually assumed that the activation energies for all reactions are depicted by a distribution of activation energies as a function of the conversion degree (Huang et al., 2017). If there is a substantial variation in activation energy over the extent of conversion, the kinetic parameters should be calculated by applying model-fitting methods with multi-step kinetic analysis in order to reproduce the reaction conversion (Vyazovkin et al., 2011).

With regards to model-fitting methods, the Distributed Activation Energy Model (DAEM) is an accurate, versatile and powerful tool for assessing the devolatilization kinetic process of different complex feedstocks such as coal (Pitt, 1962) or sewage sludge (Scott et al., 2006). DAEM has been previously pointed out by Varhegyi et al., (2002) as the best method available for mathematically representing the physical and chemical heterogeneity of biomass during a devolatilization process, and it has been successfully applied to woody biomass, including its major constituents (lignin, cellulose and hemicellulose) (Navarro et al., 2009), among others. DAEM is a multireaction model that assumes that the decomposition mechanism occurs through a large number of independent, parallel, first order or nth-order reactions with different 
activation energies reflecting variations in the bond strengths of species (Cai et al., 2014; Wang et al., 2017). The energy distribution of these reactions can be represented by a continuous function, such as Gaussian distribution, the Weibull distribution, the Fraser-Suzuki function and the logistic function (Wang et al., 2017), or also by a discrete distribution (Scott et al., 2006), which does not need a continuous function for the activation energy.

Isoconversional methods and DAEM have become an attractive alternative with which to perform a complete study of the pyrolysis kinetics of biomass derived from fruit peels. These methods have mainly been applied to conventional types of biomass and the literature is scarce as regards the feedstocks studied here. It is therefore of interest to assess how pyrolysis occurs and how comparable/reproducible the results of these methods will be when applied to different kinds of biomass. Literature shows works using isoconversional methods to determine the activation energy of different fruit peel wastes (Qiu et al., 2015; Sánchez et al., 2016; Tahir, et al., 2019) and lignocellulosic byproducts (Mishra and Mohanty, 2018; He at al., 2019) but there are no works, as the best authors' knowledge, using combined isoconversional methods and the DAEM approach given in this work to study and compare kinetics of fruit peels and lignocellulosic biomass.

\section{Materials and methods}

\subsection{Feedstock}

Five biomass wastes - pineapple peel (PP), orange peel (OP), mango peel (MP), rice husk $(\mathrm{RH})$ and pine wood $(\mathrm{PW})$ - were used in this work. Once collected, all samples were dried at $105^{\circ} \mathrm{C}$ for $24 \mathrm{~h}$ in order to avoid the possible alteration of the main constituents. Elemental, proximate, heating value and extractive analyses were 
conducted on the five samples. Elemental analysis was performed using a Thermo Scientific Flash 2000 device. Proximate analysis was carried out according to the Spanish UNE-CEN/TS 14774-3 ex and UNE-CEN/TS14775 ex standards for determining moisture and ash content, respectively, while volatile matter was measured according to the oven-drying method specified by the ISO 5623:1974 standard. Fixed carbon was determined by difference. The higher heating value (HHV) was determined by applying the ASTM 240-09 standard using an IKA C2000 oxygen bomb calorimeter. Finally, extractives were quantified using the Tappi test method T $204 \mathrm{~cm}-17$ for determining solvent extractives of wood and pulp.

\subsection{Thermogravimetric analysis}

TGA was performed under atmospheric pressure using a Q50 analyser (TA Instruments) at three different heating rates $\left(5^{\circ} \mathrm{C}, 10^{\circ} \mathrm{C}\right.$ and $\left.20^{\circ} \mathrm{C} / \mathrm{min}\right)$. In all cases, the sample weight was fixed at $10 \mathrm{mg}$, while the particle size and the $\mathrm{N}_{2}$ flow rate were 177-250 $\mu \mathrm{m}$ and $150 \mathrm{~mL} / \mathrm{min}$, respectively. The thermobalance was purged with $\mathrm{N}_{2}$ for $10 \mathrm{~min}$ before starting the heating programme from room temperature to $700^{\circ} \mathrm{C}$. The temperature range for kinetic studies was taken as $110-700^{\circ} \mathrm{C}$ as only moisture and physically absorbed water is removed at temperatures below $110^{\circ} \mathrm{C}$ and there is negligible weight loss after $700^{\circ} \mathrm{C}$. The experimental conversion $\left(X_{\text {exp }}\right)$ was calculated from equation (1).

Where $m_{i}$ is the initial mass of sample $(\mathrm{mg}) ; m$ is the sample mass at time $t(\mathrm{mg})$; and $m_{f}$ is the sample mass $(\mathrm{mg})$ at $700^{\circ} \mathrm{C}$.

\subsection{Isoconversional methods}


Five isoconversional methods were implemented in this work: (i) Kissinger-AkahiraSunose (KAS), (ii) Flynn-Wall-Ozawa (FWO), (iii) Starink and (iv) Vyazovkin, all them in the integral form, while (v) the Friedman method was used in the differential form. Table 1 shows the mathematical expressions of these methods. These isoconversional methods enabled estimation of $E_{a}$ at different conversion values, avoiding the uncertainty introduced by the reaction model assumption. Other kinetic parameters require knowledge of the reaction model. The conversion range used for obtaining the activation energy distribution was $10-90 \%$, as recommended elsewhere (Vyazovkin et al., 2011).

\section{Table 1}

\subsection{Distributed activation energy model}

DAEM describes the pyrolysis of complex feedstocks as many parallel decomposition reactions related to many different chemical groups. In this work, the algorithm developed by Scott et al., (2006) was implemented in a Fortran subroutine to solve this model. Thus, the unique triplet that characterizes each chemical group by its activation energy and pre-exponential factor of a first-order reaction was determined. This algorithm solves the kinetics of such reactions provided that only one reaction is dominating the overall loss of mass at the conversion of interest, as shown in equation (9).

Where $X$ is the conversion degree; $f_{\mathrm{i}, 0}$ is the mass-fraction of $m_{i}$ that decomposes with an activation energy $E_{a, i}(\mathrm{~kJ} / \mathrm{mol})$ and a pre-exponential factor $A_{i}\left(\mathrm{~s}^{-1}\right) ; t$ is time $(\mathrm{s}) ; T$ is temperature $(\mathrm{K})$; and $R$ is the ideal gas constant $(\mathrm{kJ} / \mathrm{mol} . \mathrm{K})$. Using experimental 
measurements of mass of sample at time $t(m)$ at two different heating rates, the kinetic parameters of $E_{a i}, A_{i}, f_{0, i}$, were evaluated at 81 equally spaced intervals of conversion, corresponding to the conversion range of $10-90 \%$ with a step size of 1 . The TGA data of heating rates of $5^{\circ} \mathrm{C}$ and $10^{\circ} \mathrm{C} / \mathrm{min}$ were used in the model for determining the parameters then used to predict data at the heating rate of $20^{\circ} \mathrm{C} / \mathrm{min}$.

\subsection{Statistical treatment}

The deviation in the determination of $E_{a}$ for each sample using the KAS, FWO, Starink and Friedman methods was calculated from the regression coefficient $\left(R^{2}\right)$. Likewise, the resulting deviation in the Vyazovkin method was performed by calculating a percentage error $(P E)$ between the predicted values when equation (5) is minimized and the resulting value from $\mu(\mu-1)$ (Vyazovkin, 1996).

On the other hand, application of DAEM enabled a simulated pattern to be obtained for the thermal degradation of each feedstock, which was validated by using the experimental TGA obtained at $20^{\circ} \mathrm{C} / \mathrm{min}$. The deviation between the experimental and the simulated results from DAEM was assessed using mean absolute percentage error (MAPE), as expressed in equation (10). MAPE has been used to determine the goodness of fit of different structural models for biomass char gasification kinetics, as shown by Kramb et al. (2014).

Where $g$ is the number of data points.

\section{Results and discussion}

\subsection{Feedstock characterization}


Table 2 shows the elemental, proximate, heating value and extractive analyses of the five biomass wastes considered in this work. As expected, all samples show intermediate carbon content (41.13-49.70 wt\%), while oxygen content is quite high (33.58-44.40 wt\%). Hydrogen, nitrogen and sulphur content is relatively similar, with no major differences between them. In general terms, all these elements come from the main organic constituents of biomass such as cellulose, hemicellulose and lignin, as well as fractions of extractives (Sharma et al., 2015). Similarly, the volatile matter content for all samples is relatively high (75.38-82.82 wt\%), enhancing their potential use as feedstock in pyrolysis processes for bio-oil production (Sait et al., 2012). Moreover, the ash content is very high for RH (17.01 wt $\%)$, while in the rest of samples it is relatively comparable $(2.82-5.21 \mathrm{wt} \%)$, except for $\mathrm{PW}$, which is very low $(0.64$ $w t \%)$. The HHV for the fruit peel wastes and agro-industrial by-products are between 18.36 and $19.02 \mathrm{MJ} / \mathrm{kg}$, and 15.30 and $20.37 \mathrm{MJ} / \mathrm{kg}$, respectively. On the other hand, the extractive contents vary notably between the fruit peel wastes and the agro-industrial by-products. The extractive contents of $\mathrm{PP}, \mathrm{OP}$ and $\mathrm{MP}$ are $33.33 \mathrm{wt} \%, 34.53 \mathrm{wt} \%$ and $29.42 \mathrm{wt} \%$, respectively; while their proportion in $\mathrm{RH}$ and $\mathrm{PW}$ is $9.36 \mathrm{wt} \%$ and 10.56 $\mathrm{wt} \%$, respectively.

\section{Table 2}

\subsection{Pyrolysis pattern}

Fig. 1 shows the weight and the rate of weight loss for all samples at three different heating rates $\left(5^{\circ} \mathrm{C}, 10^{\circ} \mathrm{C}\right.$ and $\left.20^{\circ} \mathrm{C} / \mathrm{min}\right)$. All fruit peel wastes show a relatively similar pattern. The first low peak is associated with the release of weakly bonded water. Then, two main peaks with maxima before $200^{\circ} \mathrm{C}$ and after $300^{\circ} \mathrm{C}$ remain almost equal for these three feedstocks, although intermediate shoulders or low peaks also appear 
between them, depending on the fruit peel waste. As they are biomass, they form a complex solid mainly composed of hemicellulose, cellulose, lignin (Wang et al., 2017) and inorganic compounds such as alkali metals (Sharma et al., 2015). These samples also present important fractions (around $30 \mathrm{wt} \%$ of composition, see Table 2) of extractives, (waxes, fats, resins, tannin, simple sugars, pectins and phenolic compounds, among others) that affect the decomposition profile since they show a wide decomposition range $\left(150-600^{\circ} \mathrm{C}\right)$.

As observed in Fig. 1, the degradation profile of these extractives overlaps with those from hemicellulose, cellulose and lignin (Guo et al., 2010; Özsin and Pütün, 2017). The decomposition pathway of the fruit peel wastes starts at around $150^{\circ} \mathrm{C}$ with the hydrolysis of certain extractives (White et al., 2011), which are less stable and start to degrade at lower temperatures due to their higher volatility (Shebani et al., 2008; Părpăriţă et al., 2014). The decomposition of hemicellulose could be related to the secondary peak observed for PP and shoulders for OP and MP between $200^{\circ} \mathrm{C}$ and $300^{\circ} \mathrm{C}$ (Părpăriţă et al., 2014). The main fast devolatilization of the cellulose component between $300^{\circ} \mathrm{C}$ and $350^{\circ} \mathrm{C}$ produces the second main decomposition peak of the profiles (Părpăriţă et al., 2014). At higher temperatures, decomposition of the strongest bonds in the lignin takes place up to $550^{\circ} \mathrm{C}$ (Özsin and Pütün, 2017; Brebu et al., 2014).

Finally, at the highest temperatures studied, only advanced charring processes continue with a very low reaction rate (Părpăriţă et al., 2014). The residual weight observed at $550^{\circ} \mathrm{C}$ is about $28 \mathrm{wt} \%$ for these samples, while the final residual weight at $700^{\circ} \mathrm{C}$ is about $25 \mathrm{wt} \%$, indicating that the decomposition process is almost finished at $550^{\circ} \mathrm{C}$. Similar behaviour in the TGA pattern was also reported by Pathak et al., (2017) for different fruit peel wastes including banana, orange, citrus, lemon and jackfruit. Tahir et 
al., (2019) and Sánchez el al., (2016) also shown a very similar TGA profile for banana peels and pineapple peels, respectively. In addition, it is worth highlighting that the content and character of extractives vary from type to type of biomass, even varying between different parts of each plant (Pecha and Garcia-Perez, 2015). With regard to RH and the PW, which have a much lower content in extractives (Table 2), thermal decomposition is mainly assigned to the degradation of cellulose, hemicellulose and lignin. In this case, all of them are superimposed onto a same shoulder peak between $250^{\circ} \mathrm{C}$ and $400{ }^{\circ} \mathrm{C}$. These results are similar to those reported by Zhang et al., (2016) for RH as well as those showed by Puy et al., (2011), Mishra and Mohanty (2018), and He at al., (2019) for PW.

Fig. 1

Fig. 2 shows the comparison of the rate of weight loss for all samples at $20^{\circ} \mathrm{C} / \mathrm{min}$. As observed, the maximum rate of weight loss for all the fruit peel wastes occurred close to $200^{\circ} \mathrm{C}$, while this temperature is higher for $\mathrm{RH}$ and $\mathrm{PW}$, at around $350^{\circ} \mathrm{C}$ and $380^{\circ} \mathrm{C}$, respectively. The different trends of rate weight loss for the fruit peel wastes and agroindustrial by-products are attributed to the composition, particularly cellulose, hemicellulose, lignin and extractive components. As shown in Table 2, the fruit peel wastes studied in this work showed higher extractives and hence, lower content in cellulose, hemicellulose and lignin than that found in lignocellulosic biomass, RH and PW, as reported elsewhere (Guo et al., 2010; Zhang et al., 2016; Mishra and Mohanty 2018).

Fig. 2 


\subsection{Isoconversional methods}

The $E_{a}$ calculated for all the isoconversional methods considered in this work was obtained by linear regression. The plot of $\operatorname{Ln}\left(\beta / T^{2}\right)$ for the KAS method, the plot of $\operatorname{Ln}$ ( $\beta$ ) for the FWO method, the plot of $\operatorname{Ln}\left(\beta / T^{1.92}\right)$ for the Starink method and the plot of $\operatorname{Ln}(\beta(d X / d T))$ for the Friedman method, all them vs. $1000 / \mathrm{T}\left(\mathrm{K}^{-1}\right)$, enabled to find the $E_{a}$ using the TGA results for a conversion range between $10 \%$ and $90 \%$, using a step size of 5. For example, Fig. 3 shows these adjustments for MP. Table 3 shows the minimum and maximum $R^{2}$ obtained for each feedstock and each isoconversional method (each model has $17 R^{2}$ values for each sample). As observed, all the adjustments present a high $R^{2}$, greater than 0.8217 . The Vyazovkin method is not shown in Fig. 3 because $E_{a}$ was determined by minimization of Eq. (5). As previously mentioned, $P E$ was used as a deviation indicator for this isoconversional method, resulting in values lower than $7.8042 \%$ (Table 3).

\section{Fig. 3}

\section{Table 3}

Fig. 4 shows $E_{a}$ distribution against $X$ of all feedstock for the KAS, FWO, Starink, Friedman and Vyazovkin methods and a comparison of them applying KAS method. As observed, $E_{a}$ profiles are quite comparable for all isoconversional methods. In this sense, the $E_{a}$ profiles of both fruit peel wastes and agro-industrial by-products for the KAS, FWO, Starink and Vyazovkin methods are practically the same. Since these methods are based on an integral form, there are some approximations associated with the temperature function (Jankovic, 2008; Mishra et al., 2015). However, the $E_{a}$ profiles from the Friedman method are slightly different from those obtained using the other 
isoconversional methods. The Friedman method is based on the simple differential form of the kinetic rate law and involves no oversimplified approximation to assess the temperature function (Mishra et al., 2015). In addition, the Friedman method is not limited to the use of the linear variation of the heating rate (Cai et al., 2018).

\section{Fig. 4}

In relation to the different $E_{a}$ distributions obtained for the five samples, the fluctuations observed suggest the appearance of complex multi-step reactions including parallel, competitive and consecutive reactions (Vyazovkin et al., 2011). Different trends can be appreciated for each biomass type, as expected. In general terms, $E_{a}$ changes notably as conversion increases for fruit peel wastes for the whole range of conversion studied, while it remains fairly stable for the agro-industrial by-products up to $80 \%$ conversion. The wide variation in $E_{a}$ profiles are attributed to changes in the decomposition mechanism given the proportions of reactive compounds as well as the occurrence of possible secondary reactions such as cooking/charring (Chen et al., 2015).

PP shows an $E_{a}$ profile tending to increase gradually with conversion (from 120 to 250 $\mathrm{kJ} / \mathrm{mol}$ ), with a brief and smooth decrease at $55 \%>X>75 \%$. OP and the MP show a similar pattern. The $E_{a}$ increases slowly with conversion and achieves a maximum around $400 \mathrm{~kJ} / \mathrm{mol}$ for OP and $350 \mathrm{~kJ} / \mathrm{mol}$ for MP when conversion is around $50 \%$. After that, the $E_{a}$ decreases slowly at conversions around $70 \%$ and $75 \%$ for OP and MP, respectively; and then increases again. Furthermore, the $E_{a}$ profiles for RH and PW are stable within a wide conversion range $(10 \%<X<80 \%)$ with $E_{a}$ around $170 \mathrm{~kJ} / \mathrm{mol}$ for $\mathrm{RH}$ and $180 \mathrm{~kJ} / \mathrm{mol}$ for PW. In both cases, $E_{a}$ increases at high conversions (around $80 \%$ ), reaching values around $300 \mathrm{~kJ} / \mathrm{mol}$ for both feedstocks. The $E_{a}$ found by Mishra and Mohanty (2018) was also around $170 \mathrm{~kJ} / \mathrm{mol}$ for three waste sawdust biomasses 
obtained using different isoconversional methods (KAS, FOW, Friedman and CoatsRedfern) between $10 \%$ and $70 \%$ conversion. Similarly, He et al., (2019), reported an $E_{a}$ profile around $170 \mathrm{~kJ} / \mathrm{mol}$ (between $10 \%$ and $70 \%$ conversion) for the pyrolysis of $\mathrm{PW}$. This value seems to increase after $70 \%$ conversion, especially when the Friedman method is used. The high $E_{a}$ at conversion higher than $80 \%$, obtained at temperatures higher than $350^{\circ} \mathrm{C}$, is related to the more difficult decomposition of the strongest bonds in the lignin content (Brebu et al., 2014; Özsin and Pütün, 2017) as well as possible cooking/charring reactions at higher conversions (Părpăriţă et al., 2014). In summary, although not at all conversion degrees, the fruit peel wastes showed the highest $E_{a}$ values as compared to those of the agro-industrial by-products for most of the decomposition process. These results are in line with those values reported in literature by Sánchez et al., (2016) for fruit peels and by Mishra and Mohanty (2018) and He et al., (2019) for agro-industrial by-products.

\subsection{Discrete distributed activation energy model}

Unlike isoconversional methods, model-fitting methods as DAEM allows the prediction of the kinetic pyrolysis behaviour of complex feedstock such as those studied in this work. In this sense, Fig. 5 depicts the results of kinetic parameters $\left(E_{a}, A\right.$ and $\left.f\right)$ obtained from the model application to the TGA experiments at 5 and $10^{\circ} \mathrm{C} / \mathrm{min}$ for all feedstocks. In addition, a comparison of the $E_{a}$ profiles obtained is introduced. As observed, the $E_{a}$ profiles are consistent with the results obtained from the isoconversional methods (Fig. 4), particularly for the agro-industrial by-products. These profiles show notable changes in the $E_{a}$ distribution with conversion for the fruit peel wastes and stable lower activation energies for the agro-industrial by-products. The $E_{a}$ distributions obtained for the fruit peel wastes show the same fluctuating trend in the 
whole range on conversions as those calculated by isoconversional methods, although for the OP exhibited a wider and tallest peak between $20 \%$ and $70 \%$ conversion. These differences in the values obtained by model-free methods and DAEM suggest that the higher complexity of the fruit peel samples affects $E_{a}$ determination. On the other hand, $E_{a}$ distributions calculated for the agro-industrial by-products are stable up to conversions of $80 \%$. They perfectly reproduce the $E_{a}$ distributions obtained with isoconversional methods. By DAEM application as well as by isoconversional methods, the fruit peel wastes showed the highest $E_{a}$ values as compared to those of the agroindustrial by-products. These higher values indicate higher requirement of energy to process fruit peels completely that should be taken into account when designing pyrolysis systems.

Fig. 5

Fig. 5 also shows the pre-exponential factor $(A)$ and the resulting fraction of mass $(f)$ associated with every reaction. The $A$ profiles are very similar to those found for $E_{a}$, which is ascribed to the so-called energy compensation effect (Navarro et al., 2009; Vyazovkin et al., 2011; Chen et al., 2015). With regard to $f_{i}$, none of the reactions for PP, OP or MP have associated fractions higher than 0.10 . Therefore, the pyrolysis process for fruit peel wastes seems to be characterized by 24 to 32 dominating reactions. Although hemicellulose, cellulose and lignin intervene, these reactions are mainly associated with the complex distribution and content of extractives in the fruit peel wastes. On the contrary, RH and PW show maximum mass fractions of 0.50 and 0.30 , respectively. Fig. 5 also reveals that in both cases, more than $50 \%$ of the reactions take place through the reactions described at $60 \%$ and $69 \%$ of conversion, respectively, which have been assigned to conversion of cellulose component of the lignocellulosic 
biomass (Navarro et al., 2009). The pyrolysis of these two agro-industrial by-products seems to be described by 8 to 12 dominating reactions, mainly associated with hemicellulose, cellulose and lignin degradation (Navarro et al., 2009; Zhou et al., 2018). Both the fluctuations of $E_{a}$ throughout the entire conversion range and the higher number of relevant reactions obtained by DAEM for the fruit peel wastes, as compared to the agro-industrial by-products, described more heterogeneous and complex samples associated with a higher extractive content in the former.

\subsection{Kinetic model validation}

The $E_{a}, A$ and $f$ determined by DAEM also enabled modelling of the pyrolysis behaviour of all five feedstocks at the three heating rates studied in this work. All the experimental kinetic curves were satisfactorily reproduced with deviations between experimental and predicted data using $R^{2}$ and $M A P E$ for both the conversion and the

conversion rate compiled in Table 4 . In all cases, $R^{2}$ values are very close to 1 , while the maximum $M A P E$ is less than $2.7 \%$ and $6.4 \%$ for conversion and conversion rate, respectively.

\section{Table 4}

Fig. 6 shows the validation of kinetic parameters obtained by DAEM for the TGA experiments conducted at $20^{\circ} \mathrm{C} / \mathrm{min}$. Data from this heating rate were not included in the kinetic computations using the DAEM approach and hence, a more rigorous validation test was ensured, as suggested by Vyazovkin et al., (2011). As observed, the model perfectly simulated the temperatures required to achieve a conversion up to $90 \%$ for all the feedstocks studied. Despite some slight differences at conversions higher than $95 \%$, it should be highlighted that DAEM results for all samples (fruit peel wastes and agro-industrial by-products) at this higher heating rate show remarkably good 
agreement with the experimental data. More particularly, the model accurately reproduces the shape of conversion and reaction rate profiles with the shift to higher temperatures related to the increasing heating rate, given that the experimental and calculated profiles overlap. These results indicate the great accuracy of DAEM for predicting pyrolysis kinetics of biomass wastes of different characteristics.

Fig. 6

\section{Conclusions}

The $E_{a}$ distribution for fruit peel wastes showed a fluctuating profile throughout the entire range of conversion $(150-550 \mathrm{~kJ} / \mathrm{mol})$, while it showed a stable profile (180 $\mathrm{kJ} / \mathrm{mol}$ ) for the agro-industrial by-products up to $80 \%$ conversion. The six methods used to determine $E_{a}$ showed similar patterns. The resulting fraction of mass distributions obtained by DAEM for fruit peel wastes and agro-industrial by-products are characterized by 24 to 32 and by 8 to 12 relevant reactions, respectively. Both the fluctuating $E_{a}$ and high number of relevant reactions are associated with a high extractive content in the peel samples $(\approx 30 \mathrm{wt} \%)$.

\section{Acknowledgements}

The authors would like to express all their gratitude to COLCIENCIAS and CIDI-UPB for the financial support given by the projects 1210-715-51742 and 387C-11/18-24, respectively. We are also grateful to GIMEL group from UdeA for making the TGA device available to us, and to the GRAIN group from UPB for their support in extractives quantification. In addition, the authors would like to thank MINECO and FEDER for their financial support (Project ENE2015-68320-R) and the Regional 
Government of Aragon (DGA) for the support provided under their research groups support programme.

\section{References}

1. Ajila, C.M., Bhat, S.G., Prasada, U.J.S., 2007. Valuable components of raw and ripe peels from two India mango varieties. Food Chem. 102, 1006-1011.

2. Akahira, T., Sunose, T., 1971. Joint convention of four electrical institutes. Sci. Technol. 16, 22-31.

3. Brebu, M., Yanik, J., Uysal, T., Vasile, C., 2014. Thermal and catalytic degradation of grape seeds/polyethylene waste mixture. Cellul. Chem. Technol. 48, 665-674.

4. Cai, J., Wu, W., Liu, R., 2014. An overview of distributed activation energy model and its application in the pyrolysis of lignocellulosic biomass. Renew. Sust. Energ. Rev. 36, 236-246.

5. Cai, J., Xu, D., Dong, Z., Yu, X., Yang, Y., Banks, S.W., Bridgwater A.V., 2018. Processing thermogravimetric analysis data for isoconversional kinetic analysis of lignocellulosic biomass pyrolysis: Case study of corn stalk. Renew. Sust. Energ. Rev. 82, 2705-2715.

6. Chen, Z., Zhu, Q., Wang, X., Xiao, B., Liu, S., 2015. Pyrolysis behaviors and kinetic studies on Eucalyptus residues using thermogravimetric analysis. Energ. Convers. Manage. 105, 251-259.

7. Damartzis, Th., Vamvuka, D., Sfakiotakis, S., Zabaniotou, A., 2011. Thermal degradation studies and kinetic modeling of cardoon (Cynara cardunculus) pyrolysis using thermogravimetric analysis (TGA). Bioresour. Technol. 102, 6230-6238. 
8. FAO, 2016. Rice market monitor.

http://www.fao.org/fileadmin/templates/est/COMM_MARKETS_MONITORING/R ice/Images/RMM/RMM_APR16.pdf. (Access on 12.12.2018).

9. FAO, 2017. Citrus fruit fresh and processed. http://www.fao.org/3/a-i8092e.pdf. (Access on 12.12.2018).

10. Friedman, H.L., 1964. Kinetics of thermal degradation of char-forming platics from thermogravimetry. Application to a phenolic plastic. J. Polym. Sci., Part C: Polym Sym. 6, 183-195.

11. Flynn, J.H., Wall, L.A., 1966. A quick, direct method for the determination of activation energy from thermogravimetric data. J. Polym. Sci., Part B: Polym. Lett. $4,323-328$.

12. Guo, X.J., Wang, S.R., Wang, K.G., Liu, Q., Luo, Z.Y., 2010. Influence of extractives on mechanism of biomass pyrolysis. J. Fuel Chem. Technol. 38, 42-46.

13. Huang, Y.W., Chen, M.Q., Li, Y., 2017. An innovative evaluation method for kinetic parameters in distributed activation energy model and its application in thermochemical process of solid fuels. Thermochim Acta. 655, 42-51.

14. He, Q., Ding, L., Gong, Y., Li, W., Wei, J., Yu, G., 2019. Effect of torrefaction on pinewood pyrolysis kinetics and thermal behavior using thermogravimetric analysis. Bioresour. Technol. 208, 104-111.

15. Jankovic, B., 2008. Kinetic analysis of the nonisothemal decomposition of potassium metabisulfite using the model-fitting and isconversional (model-free) methods. Chem. Eng. J. 139, 128-135.

16. Ketnawa, S., Chaiwut, P., Rawdkuen, S., 2012. Pineapple waste: A potential source for bromelain extraction. Food Bioprod. Process. 90, 385-391. 
17. Kramb, J., Konttinen, J., Gómez-Barea, A., Moilanen A., Umeki, K., 2014.

Modeling biomass char gasification kinetics for improving prediction of carbon conversion in a fluidized bed gasifier. Fuel 132, 107-115.

18. Kissinger, H.E., 1956. Variation of peak temperature with heating rate in differential thermal analysis. J. Res. Natl. Bur. Stand. 57, 217-221.

19. Martínez, J.D., Pineda, T., López, J.P., Betancur, M., 2011. Assessment of the rice husk lean-combustion in a bubbling fluidized bed for the production of amorphous silica-rich ash. Energy 36, 3846-3854.

20. Mishra, G., Kumar, J., Bhaskar, T., 2015. Kinetic studies on the pyrolysis of pinewood. Bioresour. Technol. 182, 282-288.

21. Mishra, R., Mohanty, K., 2018. Pyrolysis kinetics and thermal behaviour of waste sawdust biomass using thermogravimetric analysis. Bioresour. Technol. 251, 63-74.

22. Navarro, M.V., Murillo, R., Mastral, A.M., Puy, N., Bartoli, J., 2009. Application of the distributed activation energy model to biomass and biomass constituents devolatilization. AIChe J. 55, 2700-2715.

23. Neves, D., Thunman H., Matos A., Tarelho L., Gómez-Barea A., 2011. Characterization and prediction of biomass pyrolysis products. Prog. Energy Combust. Sci. 37, 611-630.

24. Oberoi, H.S., Vadlani, P.V., Madi, R.L., Saida, L., Abeykoon, J.P., 2010. Ethanol production from Orange peels: two-stage hydrolysis and fermentation studies using optimized parameters through experimental design. J. Agric. Food Chem. 58, 34223429.

25. Ozawa, T., 1965. A new method of analyzing thermogravimetric data. Bull. Chem. Soc. Jpn 38, 1881-1886. 
26. Özsin, G., Pütün, A.E., 2017. Kinetics and evolved gas analysis for pyrolysis of food processing wastes using TGA/MS/FT-IR. Waste Manage. 64, 315-326.

27. Părpăriţă, E., Brebu, M., Azhar, Md., Yanik, J., Vasile, C., 2014. Pyrolysis behaviors of various biomasses. Polym Degrad. Stab. 100, 1-9.

28. Pathak, P.D., Mandavgane, S.A., Kulkarni, B.D., 2017. Fruit peel waste: characterization and its potential uses. Curr. Sci. 113, 444-454.

29. Pecha, B., Garcia-Perez, M., 2015. Pyrolysis of Lignocellulosic Biomass: Oil, Char, and Gas, in: Dahiya, A. (Eds.), Bioenergy Biomass to Biofuels, Academic Press, pp. 413-442.

30. Pérez, J.F., Pelaez-Samaniego, M.R., Garcia-Perez, M., 2017. Torrefaction of fastgrowing Colombian Wood species. Waste Biomass Valori. 1-13.

31. Pitt, G., 1962. The kinetics of the evolution of volatile products from coal. Fuel 41 , 267-274.

32. Procolombia, 2017. Colombia an export and investment platform in the Americas. http://www.portmanatee.com/wp-content/uploads/2017/06/PPT_April-20-2017.pdf. (Access on 12.12.2018).

33. Puy, N., Murillo, R., Navarro, M.V., López J.M., Rieradevall, J., Fowler, G., Aranguren, I., García, T., Bartrolí, J., Mastral, A.M., 2011. Valorisation of forestry waste by pyrolysis in an auger reactor. Waste Manage. 31, 1339-1349.

34. Qiua, H-W., Zhou, Q-C., Geng, J., 2015. Pyrolytic and kinetic characteristics of Platycodon Grandiflorum peel and its cellulose extract. Carbohyd. Polym. 117, 644649.

35. Rueda-Ordónez, Y.J., Tannous, K., 2015. Isoconversional kinetic study of the themal decomposition of sugarcane straw for thermal conversion process. Bioresour. 
Technol. 196, 136-144.

36. Sait, H.H., Hussain, A., Adam, A., Nasir, F., 2012. Pyrolysis and combustion kinetics of date palm biomass using thermogravimetric analysis. Bioresour. Technol. 118, 382-389.

37. Sánchez, J.D., Ramírez, G.E., Barajas, M.J., 2016. Comparative kinetic study of the pyrolysis of mandarin and pine apple peel. J. Anal. Appl. Pyrol. 118, 192-201.

38. Scott, S.A., Dennis, J.S., Davidson, J.F., Hayhurst, A.N., 2006. An algorithm for determining the kinetic of devolatilisation of complex solid fuel from thermogravimetric experiments. Chem. Eng. Sci. 61, 2339-2348.

39. Sharma, A., Pareek, V., Zhang, D. 2015. Biomass pyrolysis-A review of modelling, process parameters and catalytic studies. Renew. Sustain. Energy Rev. 50, 1081-1096.

40. Shebani, A.N., van Reenen, A.J., Meincken, M. 2008. The effect of wood extractives on the thermal stability of different wood species. Thermochim. Acta $471,43-50$.

41. Starink, M.J., 1996. A new method for the derivation of activation energies from experiments performed ar constant herating rate. Thermochim. Acta 288, 97-104.

42. Tahir, M.H., Zhao, Z., Ren, J., Rasool, T., Naqvi, S.R., 2019. Thermo-kinetics and gaseous product analysis of banana peel pyrolysis for its bioenergy potential. Biomass Bioenerg. 122, 193-201

43. Varhegyi, G., Szabó, P., Antal, M.J., 2002. Kinetics of charcoal devolatilization. Energ. Fuel 16; 724-731.

44. Vyazovkin, S., 1996. A unified approach to minetic processing of nonisothermal data. Int. J. Chem. Kinet. 28 , 94-101. 
45. Vyazovkin, S., Wight, C.A., 1999. Model-free and model-fitting approaches to kinetic analysis of isothermal and noisothermal data. J. Chem. Inf. Comput. Sci. $340-341,53-68$.

46. Vyazovkin, S., Burnham, A.K., Criado, J.M., Pérez-Maqueda, L.A., Popescu, C., Sbirrazzuoli, N., 2011. ICTAC Kinetics Committee recommendations for performing kinetic computations on thermal analysis data. Thermochim. Acta 520, $1-19$.

47. Wang, S., Dai, G., Yang, H., Luo, Z., 2017. Lignocellulosic biomass pyrolysis mechanism:A state-of-the-art review. Prog. Energy Combust. Sci. 62, 33-86.

48. White, J.E., Catallo, W.J., Legendre, B.L., 2011. Biomas spyrolysis kinetics: A comparative critical review with relevant agricultura residual case studies. J. Anal. Appl. Pyrol. 91, 1-33.

49. Zhang, S., Dong, Q., Zhang, L., Xion, Y., 2016. Effects of water washing and torrefaction on the pyrolysis behavior and kinetics of rice husk through TGA and Py-GC/MS. Bioresour. Technol. 199, 352-361.

50. Zhou, B., Zhou, J., Zhang, Q., 2018. Research on pyrolysis of Camellia sinesis branches via the discrete distributed activation energy model. Bioresour. Technol. 241, 113-119. 
Table 1. Isoconversional methods used in this work

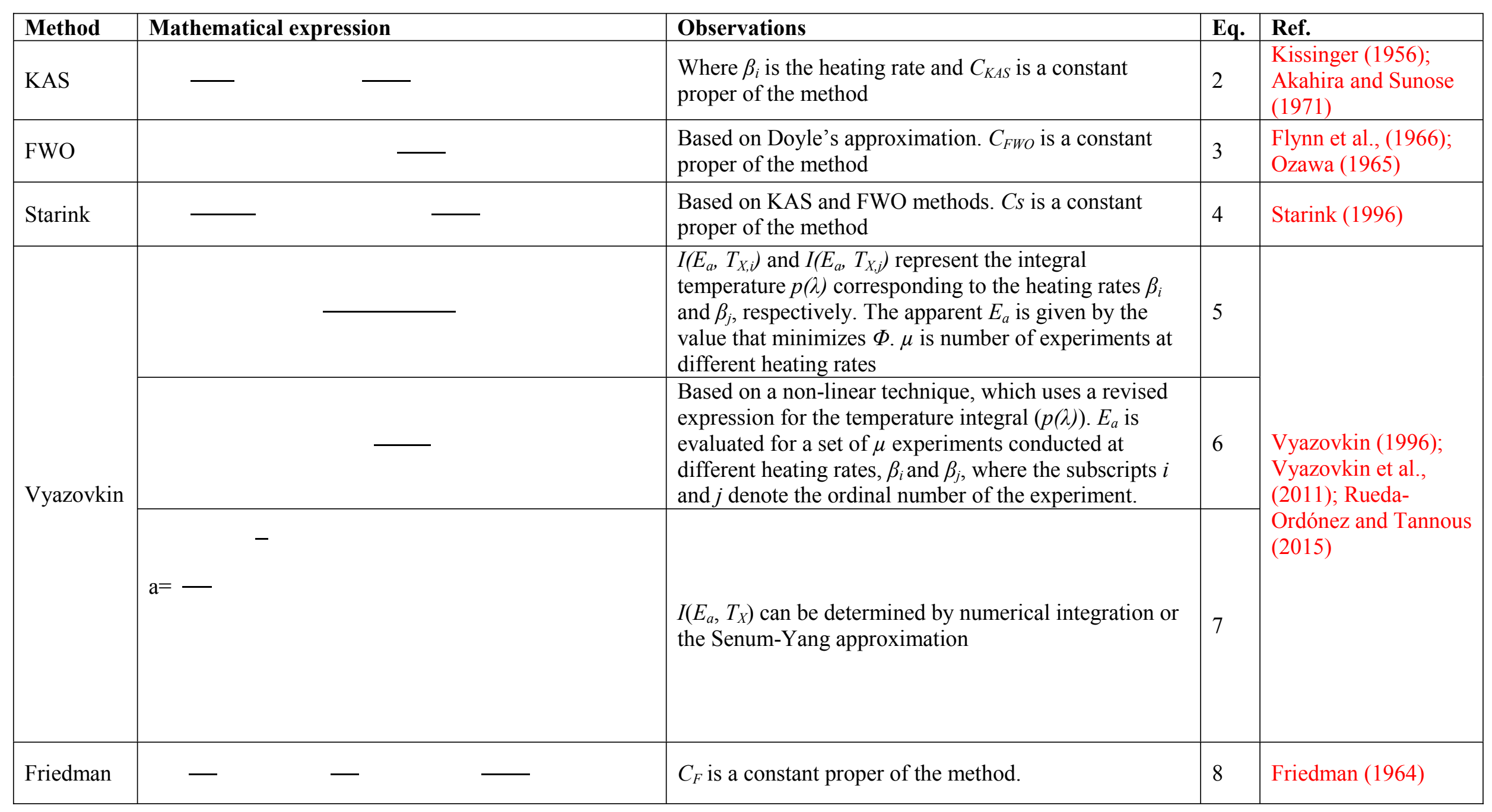


Table 2. Elemental, proximate, extractives and heating value analyses

\begin{tabular}{|c|c|c|c|c|c|c|c|c|c|c|}
\hline \multirow{2}{*}{ Feedstock } & \multicolumn{5}{|c|}{ Elemental analysis db (wt\%) } & \multicolumn{3}{|c|}{ Proximate analysis db (wt\%) } & \multirow{2}{*}{$\begin{array}{l}\text { Extractives } \\
\text { db }(w t \%)\end{array}$} & \multirow{2}{*}{$\begin{array}{l}\text { HHV db } \\
\text { (MJ/kg) }\end{array}$} \\
\hline & $\mathbf{C}$ & $\mathbf{H}$ & $\mathbf{O}$ & $\mathbf{N}$ & $\mathbf{S}$ & VM & A & FC & & \\
\hline $\mathrm{PP}$ & 45.79 & 5.31 & 33.58 & $<0.10$ & $<0.10$ & 75.38 & 5.21 & 19.61 & 33.33 & 19.02 \\
\hline $\mathrm{OP}$ & 46.04 & 5.54 & 36.89 & 0.65 & $<0.10$ & 79.02 & 3.43 & 17.54 & 34.53 & 18.57 \\
\hline MP & 47.31 & 5.77 & 35.78 & $<0.10$ & $<0.10$ & 78.78 & 2.82 & 18.54 & 29.42 & 18.36 \\
\hline $\mathrm{RH}$ & 41.13 & 3.37 & 38.17 & 0.33 & $<0.10$ & 71.28 & 17.01 & 11.72 & 10.56 & 15.30 \\
\hline PW & 52.99 & 6.30 & 40.59 & 0.13 & $<0.10$ & 82.82 & 0.64 & 16.54 & 9.36 & 20.37 \\
\hline
\end{tabular}

VM: Volatile Matter, A: Ash, FC: Fixed Carbon, C: Carbon, H: Hydrogen, O: Oxygen, N: Nitrogen; S: Sulphur, db: dry basis, HHV: Higher Heating Value. 
Table 3. Deviation parameters in the adjustment of the isoconversional methods

\begin{tabular}{|c|c|c|c|c|c|c|c|c|c|c|}
\hline \multirow{3}{*}{ Feedstock } & \multicolumn{8}{|l|}{$R^{2}$} & \multirow{2}{*}{\multicolumn{2}{|c|}{$\begin{array}{l}P E(\%) \\
\text { Vyazovkin }\end{array}$}} \\
\hline & \multicolumn{2}{|l|}{ KAS } & \multicolumn{2}{|l|}{ FWO } & \multicolumn{2}{|c|}{ Starink } & \multicolumn{2}{|c|}{ Friedman } & & \\
\hline & Min & Max & Min & Max & Min & Max & Min & Max & Min & Max \\
\hline PP & 0.8314 & 0.9991 & 0.8406 & 0.9964 & 0.8318 & 0.9991 & 0.8287 & 1.0000 & 0.0380 & 7.8042 \\
\hline $\mathrm{OP}$ & 0.8815 & 0.9960 & 0.8861 & 0.9964 & 0.8817 & 0.9960 & 0.8912 & 0.9962 & 0.1740 & 5.5461 \\
\hline MP & 0.9641 & 1.0000 & 0.9656 & 1.0000 & 0.9642 & 1.0000 & 0.9690 & 0.9998 & 0.0005 & 1.6624 \\
\hline RH & 0.9992 & 1.0000 & 0.9993 & 1.0000 & 0.9992 & 1.0000 & 0.9970 & 1.0000 & 0.0008 & 0.0351 \\
\hline PW & 0.9981 & 1.0000 & 0.9982 & 1.0000 & 0.9981 & 1.0000 & 0.9984 & 1.0000 & 0.0006 & 0.0856 \\
\hline
\end{tabular}


Table 4. Fitting deviations for DAEM

\begin{tabular}{|l|l|l|l|l|l|}
\hline \multirow{3}{*}{$\begin{array}{l}\boldsymbol{\beta} \\
\left({ }^{\circ} \mathbf{C} / \mathbf{m i n}\right)\end{array}$} & \multirow{2}{*}{ Feedstock } & \multicolumn{2}{l|}{ Conversion } & \multicolumn{2}{l|}{ Conversion rate } \\
\cline { 3 - 6 } & & $\boldsymbol{R}^{2}$ & MAPE (\%) & $\boldsymbol{R}^{2}$ & MAPE (\%) \\
\hline \multirow{5}{*}{5} & PP & 1.0000 & 0.1207 & 0.9991 & 1.4368 \\
\cline { 2 - 6 } & OP & 1.0000 & 0.0852 & 0.9992 & 1.2464 \\
\cline { 2 - 6 } & MP & 1.0000 & 0.1110 & 0.9988 & 1.3162 \\
\cline { 2 - 6 } & RH & 1.0000 & 0.9039 & 0.9998 & 3.5692 \\
\cline { 2 - 6 } & PW & 1.0000 & 0.2277 & 0.9972 & 4.1965 \\
\hline \multirow{5}{*}{10} & PP & 1.0000 & 0.3357 & 0.9986 & 1.6358 \\
\cline { 2 - 6 } & OP & 0.9999 & 0.5357 & 0.9948 & 2.5809 \\
\cline { 2 - 6 } & MP & 0.9999 & 1.9675 & 0.9864 & 3.3803 \\
\cline { 2 - 6 } & RH & 1.0000 & 1.1773 & 0.9993 & 5.9338 \\
\cline { 2 - 6 } & PW & 1.0000 & 0.3864 & 1.0000 & 3.1884 \\
\hline \multirow{5}{*}{20} & PP & 0.9997 & 2.5675 & 0.9781 & 3.9015 \\
\cline { 2 - 6 } & OP & 0.9995 & 1.7507 & 0.9713 & 6.3223 \\
\cline { 2 - 6 } & MP & 0.9998 & 2.6367 & 0.9662 & 5.0798 \\
\cline { 2 - 6 } & RH & 1.0000 & 1.0691 & 1.0000 & 1.0691 \\
\cline { 2 - 6 } & PW & 0.9999 & 0.5066 & 0.9946 & 4.2809 \\
\hline
\end{tabular}



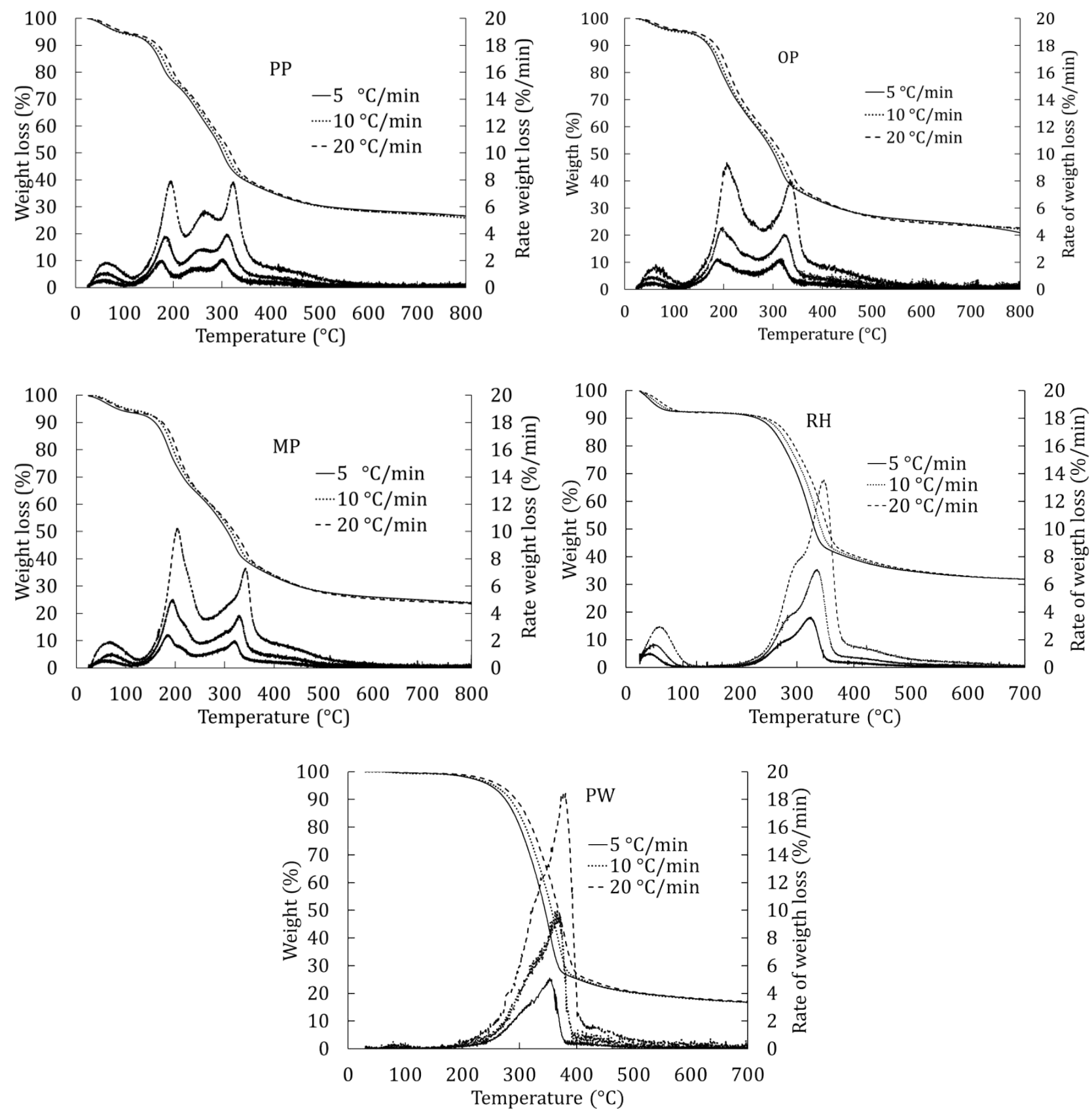

Fig. 1. Experimental TGA data 


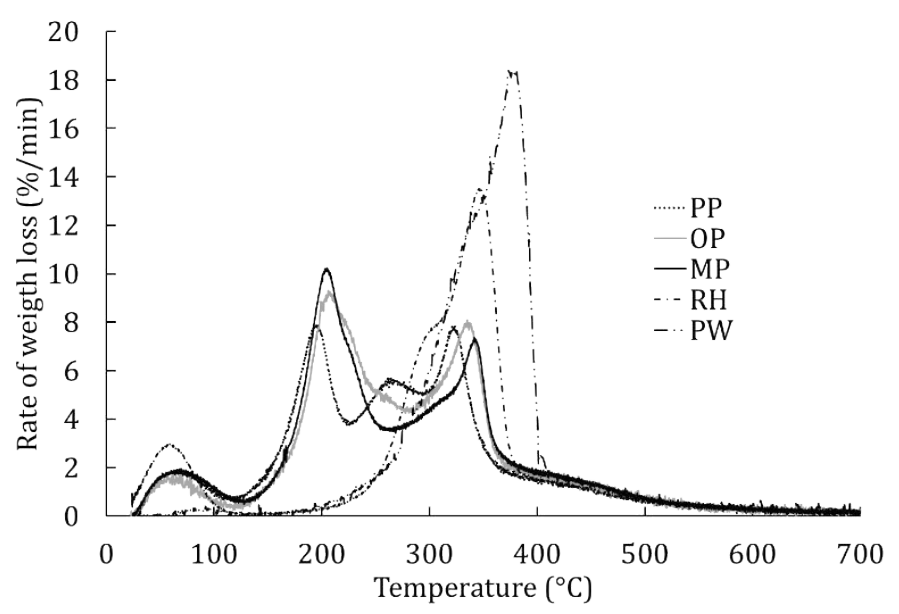

Fig. 2. Conversion rate comparison of samples at $20^{\circ} \mathrm{C} / \mathrm{min}$ 

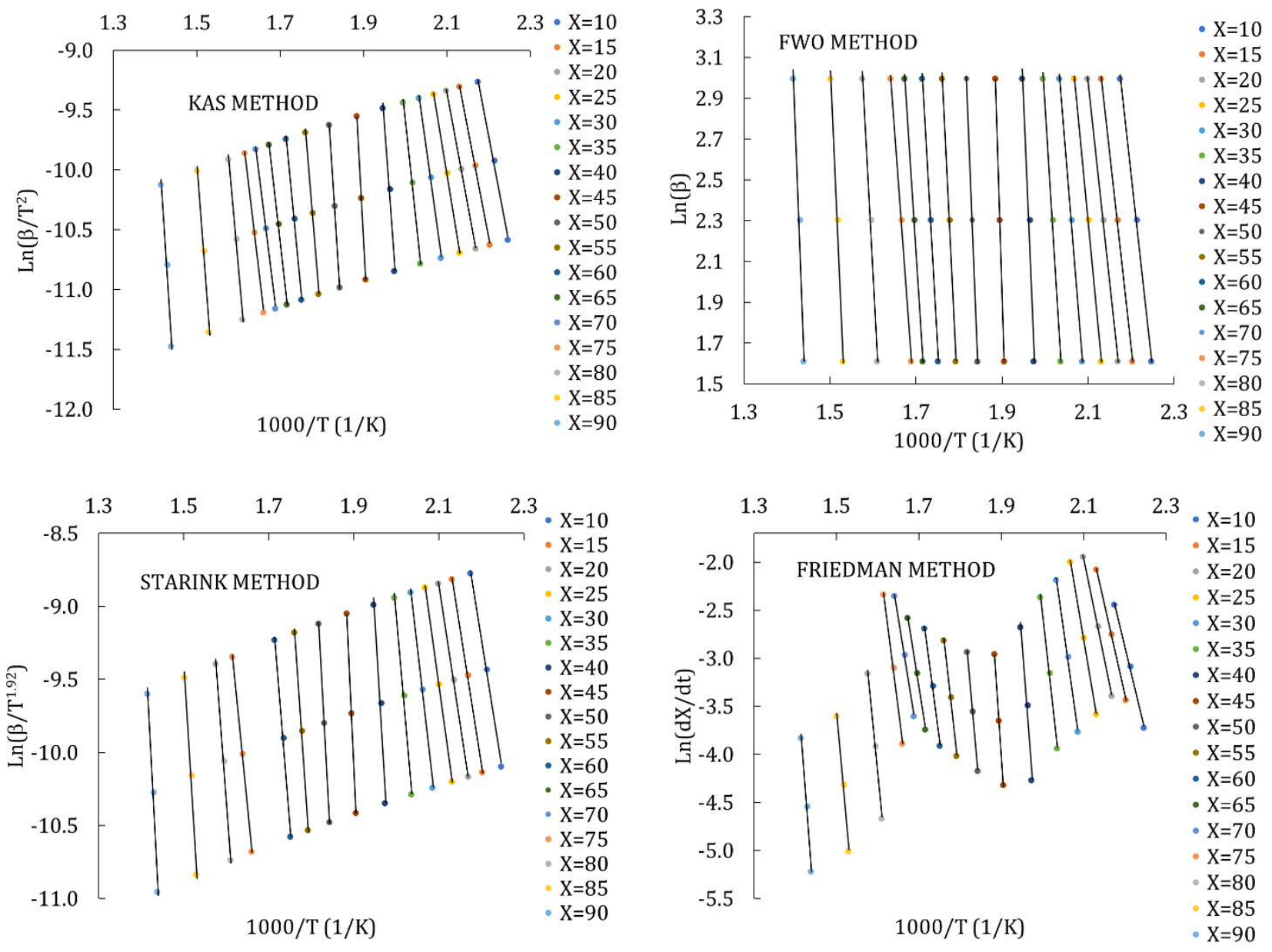

Fig. 3. Adjustment example of the isoconversional methods for MP 

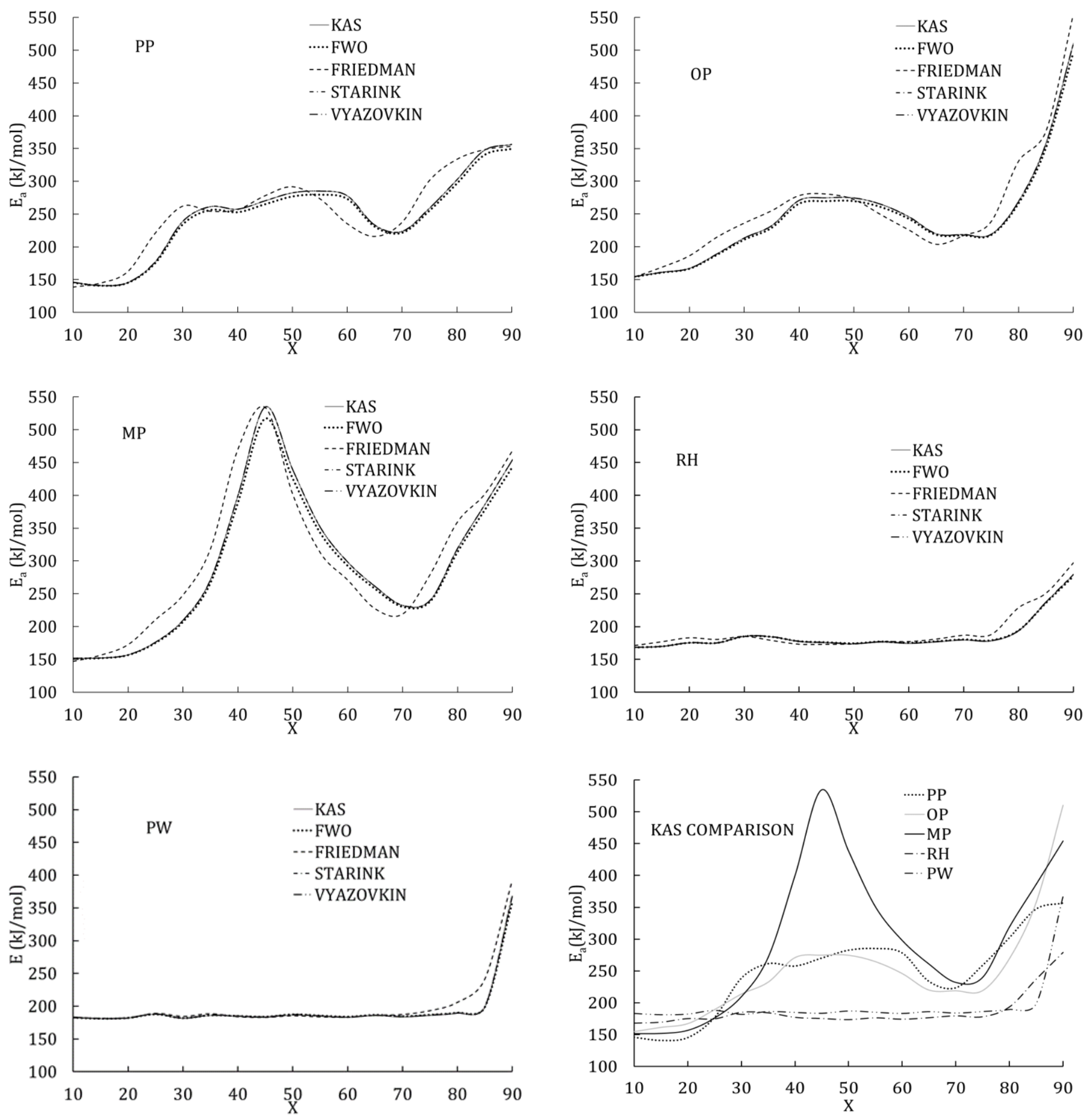

Fig. 4. $E_{a}$ distribution from isoconversional methods 

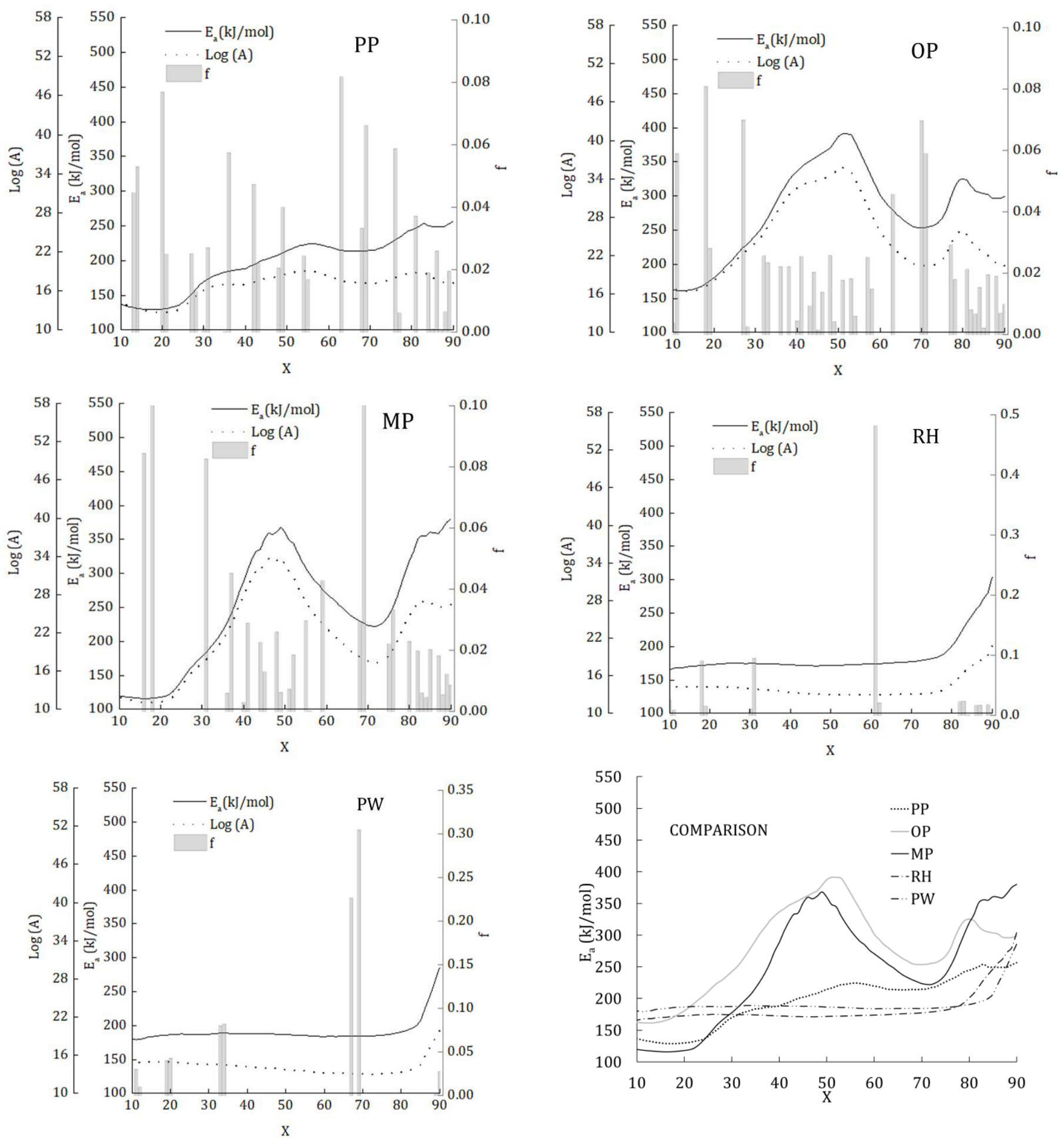

Fig. 5. Pyrolysis kinetic parameters obtained from DAEM 

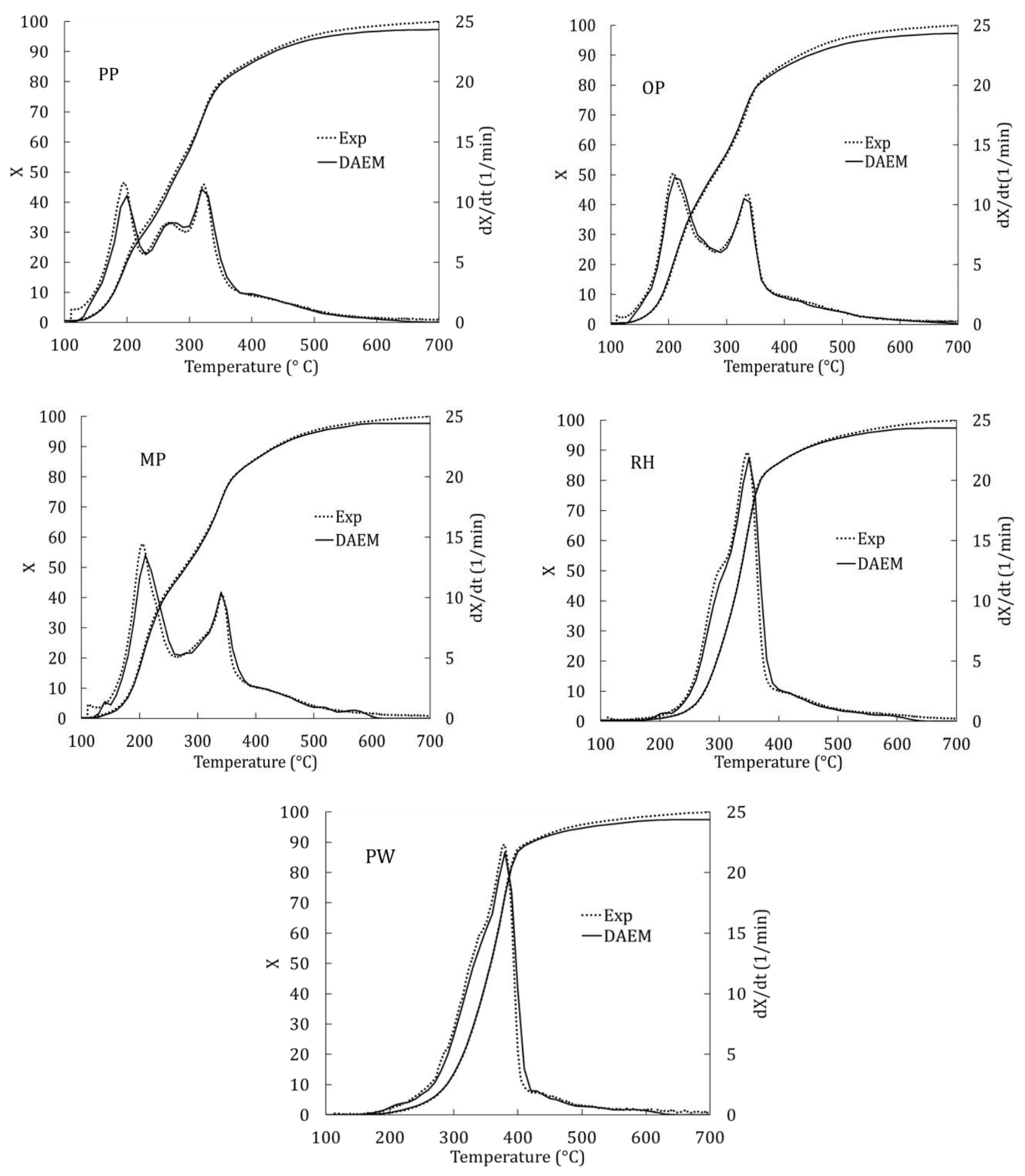

Fig. 6. Comparison between experimental data and theoretical data generated with DAEM algorithm at $20^{\circ} \mathrm{C} / \mathrm{min}$ 